\title{
La participación de los sectores populares en la guerra revolucionaria y su vínculo con la política; Tucumán en 1815
}

\section{The participation of the popular sectors in the revolutionary war and its link with politics; Tucumán in 1815}

Gabriela Paula Lupiañez y Georgina Abbate ${ }^{1}$

\section{Resumen}

El propósito de este trabajo es visibilizar a los sectores populares militarizados en la arena política de la ciudad de Tucumán, en las Provincias Unidas del Río de la Plata, Argentina. Se estudia la movilización popular de 1815 que enfrentó a dos agrupamientos políticos al interior de la ciudad. A partir del análisis de ese caso se puede decir que la participación de los sectores populares rurales en las contiendas políticas fue más temprana que la consignada en la historiografía local, además, se recogen experiencias previas de militarización en Tucumán. La apelación a los sectores populares rurales con el principio de la soberanía popular permitió al agrupamiento

1 Gabriela Lupiañez, Universidad Nacional de Tucumán, Argentina, Departamento de Historia. Correspondencia (Corresponding author): gabriela. lupianez@filo.unt.edu.ar ; Código ORCID: 0000-0002-2176-0522

Georgina Abbate, Universidad Nacional de Tucumán, Argentina. Departamento de Historia. Universidad del Norte Santo Tomás de Aquino, Tucumán, Argentina. Facultad de Ciencias Jurídicas, Políticas y Sociales. Correspondencia: (Corresponding author): georgina.abbate@filo. unt.edu.ar ; georgina.abbbate@unsta.edu.ar 
La participación de los sectores populares en la guerra revolucionaria y su vínculo con la política. Tucumán en 1815

liderado por el "gobernador revolucionario" legitimar su posición ante la representación "tradicional" del cabildo.

Palabras claves: Milicias populares, movilización popular, guerra revolucionaria, agrupamientos políticos

\section{Abstract}

The objective of this article is to make visible the militarized popular sectors in the political arena of the city of Tucumán, in the Provincias Unidas del Río de la Plata, Argentina. It focuses on the popular mobilization produced in 1815 that confronted two political groups. From the analysis of this case, it can be said that the political participation of popular sectors in political contests was earlier than the one reported in the local historiography, besides previous experiences of militarization in Tucuman are collected. The appeal to the rural popular sectors with the principle of popular sovereignty allowed the group led by the "revolutionary governor" to legitimize its position with respect to the "traditional" representation of the cabildo.

Key words: Popular militias, popular mobilization, revolutionary war, political groupings

Los acontecimientos descritos en este trabajo se insertan en una coyuntura compleja del espacio rioplatense debido a la momentánea acefalía de autoridades reconocidas como superiores por los pueblos y que habían residido en Buenos Aires, antigua capital virreinal. El 3 de abril de 1815, un pronunciamiento militar en Fontezuelas (Buenos Aires) desató una anunciada crisis política en los territorios rioplatenses que derivó en la caída del director supremo y la disolución de la primera asamblea constituyente de la región. A ello se sumó 
la amenaza de una invasión militar por parte del monarca ya restaurado en la península ibérica.

En junio de 1815, el juramento del estatuto provisional remitido desde Buenos Aires puso de manifiesto las tensiones existentes entre el cabildo y el gobernador de San Miguel de Tucumán, ciudad fundada por expediciones provenientes del Perú en los márgenes del espacio andino. Una reunión de características inéditas en las cercanías de la ciudad compuesta por una multitud integrada principalmente por milicianos habitantes del ámbito rural tucumano cuestionó las decisiones de la tradicional autoridad del cabildo al reclamar que no se habían respetado sus derechos.

¿Qué características asumió la participación de los sectores populares en la movilización de 1815 ?

La historiografía abocada al estudio de los sectores populares en Río de la Plata destacó tanto el protagonismo de los mismos en el proceso revolucionario, como la diversidad de sus intervenciones y sus modos de relación con la política. Del mismo modo, explicitó las dificultades y desafíos para construir una "historia popular de la revolución rioplatense" (Fradkin, 2008; Di Meglio, 2007). En la producción historiográfica, resultó particularmente relevante la experiencia de las invasiones inglesas que sufrió Buenos Aires en 1806 y 1807, pues el proceso de militarización que se desencadenó para su reconquista y defensa visibilizó a los sectores subalternos y a las dinámicas políticas que tuvieron continuidad durante la revolución y se extendieron a los habitantes del ámbito rural. ${ }^{2}$

2 En el espacio peruano, la relación entre guerra, política y sectores populares es estudiada por una generación de historiadores jóvenes. Al respecto, véanse Moran, D. y Aguirre (20213); Escanilla Huerta, S., Morán, D. y Silveira, A. (2012) y Morán, D. (2011). Para el caso de Montevideo, puede verse el trabajo de Pablo Ferreina (2016). 
La participación de los sectores populares en la guerra revolucionaria y su vínculo con la política. Tucumán en 1815

Los estudiosos reconocen que con la independencia, el ámbito rural rioplatense adquirió una presencia que no había tenido antes en la política, economía y sociedad. La guerra de independencia cuestionó las jerarquías coloniales (Míguez, 2016, p. 3; Halperin Donghi, 1994). Fue una "guerra revolucionaria”, como la llama Raúl Fradkin (2008), que exigió la movilización de recursos materiales y humanos sin parangón hasta ese momento y que transformó la vida cotidiana de la sociedad a partir de la acefalía real y la disputa por lograr la hegemonía entre los polos del poder leal y el insurgente. En particular referencia al espacio surandino, los estudios que abordan el caso de Tucumán se ocupan del largo plazo. Marisa Davio (2018, p. 218) señala que en Tucumán la movilización de los sectores populares resultó visible en la guerra revolucionaria en su propia tierra cuando en septiembre de 1812 enfrentaron al ejército enviado por el virrey del Perú. Por su parte, Flavia Macías y Paula Parolo (2010) calculan que a través de la organización de fuerzas, Tucumán ofreció un alto número de enrolados en las milicias, mayoritariamente de los sectores populares que rondaría los 3000 durante toda la década. En relación con la participación política de esos sectores, Gabriela Tío Vallejo (2001) considera que miembros de las milicias que lucharon en la batalla del 24 de septiembre de 1812 participan en movimientos conspirativos o sublevaciones a partir de 1819.

En este artículo, proponemos que la actividad política de los sectores populares puede observarse antes, particularmente en la crítica coyuntura de 1815, y tuvo un marcado carácter rural. La movilización de los sectores populares rurales en el espacio público no solo creció con las acciones bélicas encabezadas por líderes locales como Bernabé Aráoz que acompañaron al ejército revolucionario comandado por Manuel Belgrano en las batallas que libraron al mando del Ejército Auxiliar del Perú, sino que también se hizo visible al calor del principio de la soberanía popular. Esto se manifestó en el explícito apoyo a su 
jefe militar en la contienda política, que involucró la reunión de junio de 1815 que se analiza en esta investigación.

El abordaje se realiza con un análisis que entrecruza lo político y lo social en una escala micro. Reconocemos las dificultades que se presentan al intentar visibilizar a este grupo social tan amplio y de gran heterogeneidad en lo material, étnico y cultural. Por ello, nos atenemos a los siguientes indicadores de su presencia: no uso del "don"; no participación en oficios capitulares; existencia de intermediaciones (militar/ miliciana, eclesiástica y judicial-policial) (Davio, 2018, p. 178); cantidad y calidad de los participantes, motivaciones y la percepción de sus opositores. Utilizamos diversos tipos de fuentes que incluyen discursos oficiales, correspondencia particular y listados que cuantifican y ordenan las milicias.

El trabajo se divide en cuatro apartados. En el primero, damos cuenta del modo en que aparecen los sectores populares con antelación a los sucesos que nos ocupan y su militarización en el espacio local. En el segundo apartado precisamos la coyuntura política en que se desarrolló la movilización que nos interesa analizar y hacemos referencia a la dinámica de los agrupamientos políticos propia del modo de hacer política en las repúblicas decimonónicas mientras que, en el siguiente, analizamos la inédita reunión multitudinaria en sí misma y sus efectos. Finalmente, proponemos un balance de lo analizado.

\section{Militarización, sectores populares y guerra revolucio- naria. La batalla de 1812}

En las ciudades de la monarquía hispana, las milicias eran unidades de carácter territorial que englobaban a toda la población masculina entre los 15 y 45 años de cada jurisdicción (Cansanello, 1995, p. 115). Las leyes escritas y también las costumbres locales imponían una diferenciación importante 
La participación de los sectores populares en la guerra revolucionaria y su vínculo con la política. Tucumán en 1815

en lo referente al servicio de milicia para la defensa de las fronteras: solo los "habitantes, vecinos y moradores" lo cumplían, lo que les otorgaba "derecho de petición" (p. 115). En relación con los sectores populares, José Carlos Chiaramonte (1999, p. 101) entiende que en la experiencia porteña la incorporación de gente más modesta a la vecindad tuvo por objeto eludir la presión de los sectores populares.

En Tucumán, las milicias no parecen haber sido formaciones regulares en el tiempo. Se las consideraba un ejército de reserva y rara vez fueron movilizadas. Esas características dificultan la identificación de sus miembros en ese periodo. Tío Vallejo (2001) reconoce en 1778 dos regimientos de dragones en Tucumán: un cuerpo de milicias correspondiente a la ciudad y otro de la campańa (solo para el territorio de Marapa). La autora indica que en ellos todos los oficiales eran vecinos y "como cada regimiento se reclutaba territorialmente, la estructura militar era un espejo de las familias destacadas de cada gobierno" (pp. 96-100). ${ }^{3}$ La vecindad era una calidad privilegiada y corporativa con participación

3 Tío Vallejo reconoce las dificultades para constatar el grado de militarización en Tucumán durante el periodo. Refiere proyectos de virreyes antes y después de la creación del virreinato del Río de la Plata para la protección de la frontera y el auxilio del cabildo. El virrey Vértiz modificó el plan de milicias y estableció en 1778 cuatro regimientos de dragones: de la ciudad, Marapa (Río Chico, parte de Chicligasta y de los Juárez), Monteros (Monteros y parte de Chicligasta) y La Frontera (Trancas y Burruyacu). Cada regimiento contaba por lo menos con tres compañías y sus respectivos capitanes, tenientes y subtenientes. Los capitanes de las dos primeras compañías eran a la vez el coronel y el teniente coronel del regimiento. El sargento mayor y un ayudante debían ser veteranos, es decir, miembros del ejército regular. La autora observa que la jerarquía social y las redes de parentesco se replicaban en el interior de las milicias, que carecían de sentido de cuerpo. Del mismo modo, calcula que conformaban potencialmente [cursivas añadidas] esas milicias unos dos mil hombres, lo que equivalía a 10\% de la población. 
en el ayuntamiento jurídicamente avalada en la monarquía hispana (Chiaramonte, 1999, p. 99). Pero en los hechos, el grado de inserción de las personas en la comunidad se basó en las redes personales que definían la condición de vecindad en función de la apropiación y reputación de los aspirantes. Tamar Herzog (2000) sostiene que "los municipios indianos no solían discriminar a los no vecinos” (pp. 127-128). Esto bien vale para la segunda mitad del siglo XVIII en el espacio rioplatense en general, y el tucumano en particular, cuando Río de la Plata recibió un importante ingreso de españoles peninsulares que rápidamente se integró a las familias de la elite local por la vía del matrimonio. Por otra parte, las condiciones de acceso a la vecindad eran más estrictas en la ciudad (ligadas a la propiedad en general) que en el campo, aunque durante la colonia, los vecinos rurales no elegían autoridades, a diferencia de los de la ciudad.

Las milicias tucumanas fueron convocadas a raíz de la sublevación de Túpac Amaru (1780-1781). Por orden del virrey del Perú, el pueblo de Tucumán debía enviar cien hombres. Según expresa Romina Zamora (2008), fue "la primera vez que los cuerpos de milicias disciplinadas tuvieron una actuación efectiva, más allá de realizar colectas". Su reclutamiento fue resistido entre los oficiales (todos miembros de la élite local) y entre la tropa conformada por los sectores populares. Su desempeño en el Alto Perú, en términos generales, estuvo marcado por la deserción y mal comportamiento de la tropa compuesta por la "forajida plebe" de Tucumán. Ese tipo de conducta fue caracterizada como de largo aliento en las milicias tucumanas por el gobernador del Perú Juan Martínez de Tineo (Bascary, 1997, 202-203). La tropa perteneciente a los "sectores populares" compartía la condición de subordinación a la élite, que los consideraba ajenos a sus espacios institucionales de poder, aunque no a sus vínculos cotidianos. Grupo amplio y heterogéneo, tanto material como étnicamente (mulatos, negros, indios, mestizos, blancos pobres), 
La participación de los sectores populares en la guerra revolucionaria y su vínculo con la política. Tucumán en 1815

en la vida cotidiana los sectores populares se involucraban en una amplia variedad de ocupaciones. En el campo, eran criadores, labradores, capataces, peones, jornaleros. En la ciudad, artesanos, trabajadores del servicio doméstico e incluso pequeños comerciantes o maestros artesanos. Los sectores más bajos se caracterizaban por la relación de dependencia, mientras que los sectores intermedios contaban con medios, como una parcela de tierra, un taller o un pequeño peculio que les permitía subsistir. Operativamente, la historiografía los identifica por oposición, ya que no se les aplicaba el título de "don", símbolo de honorabilidad. También los asocia con la carencia de criados (Parolo, 2008; López, 2010; Boixados y Farberman, 2015). Los miembros de los sectores populares no gozaban de la condición de ciudadanía, por lo que se encontraban excluidos de determinadas prácticas y deberes políticos, como la de ejercer oficios capitulares en la república (Herzog, 2000; Cansanello, 2008).

Recién en 1801 hubo un verdadero reglamento de milicias, que estuvo vigente hasta por lo menos la década de 1820 (Tío Vallejo, 2001, pp.101-102). Por él se creó el Regimiento de Voluntarios de Caballería de Tucumán con dos escuadrones integrados por unos seiscientos hombres en total. Sin embargo, la normativa disponía excepciones tan numerosas que solo los sectores pobres y sin patrones habrían quedado a merced del alistamiento. Las milicias regladas o disciplinadas debían tener plazas veteranas en la plana mayor y no gozaban de fueros cuando estaban fuera de servicio. Finalmente, el reglamento se puso en funcionamiento luego de sufrir modificaciones por las reales órdenes de 1804 y 1805 con una nueva concepción de la monarquía hispana y fuerte énfasis en la militarización de su territorio en pos del objetivo de conservación del mismo (Garriga, 2006).

A comienzos de julio de 1806, respondiendo al apoyo solicitado por el virrey Sobremonte, el cabildo tucumano se 
preparó para auxiliar a Buenos Aires, la capital virreinal, invadida por los ingleses. Hubo que organizar milicias que fueron armadas, vestidas y provistas de cabalgaduras con los aportes de vecinos y habitantes de Tucumán. Los diversos sectores sociales que integraban la comunidad tucumana participaron en la defensa de la monarquía, la patria y la religión frente al invasor. Así, a fines de julio, marcharon desde Tucumán tres compañías con más de cien voluntarios cada una provenientes tanto de la ciudad como del campo. En el camino hacia Buenos Aires, las tropas tucumanas se enteraron de la reconquista de la capital. La Primera Compañía de Caballería del Regimiento de Voluntarios de Tucumán fue la encargada de escoltar hasta Tucumán doscientos prisioneros británicos en coordinación con el ayudante mayor de Tucumán Juan Ramón Balcarce, quien había sido designado en el cargo en 1804 (Páez de la Torre y Bascary de Peña, 2012, p. 117). Unos cincuenta milicianos de ese regimiento fueron asignados a la vigilancia de los prisioneros británicos, cuyo alojamiento y sostén quedó a cargo del pueblo de Tucumán (Larrouy, 1910, pp. 57 y 80). ${ }^{4}$

En febrero de 1807, el cabildo tucumano envió nuevamente doscientos hombres equipados con uniformes, caballos, armas y dos meses de sueldo para la defensa de la capital hostigada una vez más por los británicos. Eran comandados por Balcarce. Como en tiempos de la rebelión de Túpac Amaru, la negativa de oficiales -cargos honoríficos de la élite- que se manifiestan enfermos, causó cierta demora en la salida de las tropas. Karina Diaco observó que éstas debieron ser entrenadas rápidamente (2002, pp. 31-32). En esa ocasión, los sectores populares junto al resto de la comunidad tucumana fueron interpelados en las proclamas, mencionados en listas de aportantes y celebraciones que tuvieron lugar con motivo de la derrota y expulsión

4 Cabildo de Tucumán al gobernador intendente de Salta y Juan Ramón Balcarce al cabildo, Tucumán 8 y 31 de marzo de 1807. 
La participación de los sectores populares en la guerra revolucionaria y su vínculo con la política. Tucumán en 1815

británica (Calvente, 2019; Lupiañez, 2018, pp. 121-23). ${ }^{5}$ Sin embargo, las milicias tucumanas no tuvieron en esos tiempos un rol político equiparable a las milicias porteñas. Estas fueron un factor de presión en el desplazamiento del virrey Sobremonte tras las invasiones inglesas y en el nombramiento de un reemplazante, y también asumieron un rol clave en la creación de un poder autónomo en 1810.

Asumido el poder provisorio por una Junta de Gobierno de Buenos Aires el 25 de mayo de 1810, esta envió ejércitos a diversos puntos del Virreinato. El comandante de la expedición del Ejército Auxiliar del Perú, coronel Francisco Antonio Ortiz de Ocampo solicitó al cabildo tucumano dos compañías de cien hombres, cada una con el título de Alabarderos. Este debía reclutar a hombres sin ocupación conocida desde los dieciocho hasta los cuarenta años, según una nueva reglamentación militar dispuesta por la junta. Según aquella, cada hombre era un soldado. ${ }^{6}$ De ese modo, el servicio de armas en Tucumán se extendió a todos sus "habitantes". Según Macías, con ese apelativo se designaba a quienes domiciliaban y habitaban el territorio (bajo jurisdicción del cabildo) y estaban afectados por el servicio de armas, aunque esto no concordaba con sus derechos políticos específicos o estatus social (Macias, 2010, p. 54). Cansanello (2008) subraya que la condición de "casa poblada" perdió importancia, sobre todo en la zona rural producto de la dinámica social, en la que no podemos dejar de señalar la guerra y la consiguiente militarización de la población (pp. 115-116).

5 El estudio de Calvente señala que la presencia de la plebe y castas en festividades religiosas fue cada vez más notoria en manifestaciones públicas de piedad, mientras que Lupiañez indica la presencia de sectores bajos en las milicias y celebraciones por la reconquista de Buenos Aires de los británicos.

6 Estimamos que es el cuerpo de granaderos que menciona Diaco (2002, pp. 33-36). 
En enero de 1811, existían dos regimientos de voluntarios de caballería de Tucumán. Estaban organizados en seis compañías con un promedio de ciento diez hombres cada uno. Se trataba, entonces, de alrededor de seiscientos sesenta hombres, cuya mayoría provenía de la campaña. En ese momento también se creó una compañía de comerciantes de Tucumán con cincuenta y un hombres. Esta última fue una milicia urbana, no reglada o disciplinada. No sabemos exactamente cuántos de los miembros de esos cuerpos se integraron efectivamente al ejército, pero se conoce que unos cuatrocientos fueron reclutados por el ayudante mayor José Tomás Alurralde para ser incorporados al ejército durante los meses que corrieron hasta octubre de $1811 .^{7}$

En agosto de 1812, en la avanzada del ejército del virrey del Perú sobre los Andes del sur, el gobernador intendente de la provincia de Salta replicó una solicitud al cabildo de Tucumán, según la cual debían ponerse a disposición todos los hombres sin distinción de condición. Esto fue obedecido, según un informe sobre reclutamiento de hombres de Río Seco en la campaña de Tucumán. ${ }^{8}$ Poco después, una comisión delegada del pueblo de Tucumán acordó con el Ejército Auxiliar del Perú al mando de Manuel Belgrano, la defensa de la ciudad. La participación de los sectores más bajos de la comunidad local fue acreditada por propios y ajenos. El cabildo local dio cuenta de haber reclutado a "todos los

7 Recomendación de ascenso de José Tomás Alurralde que hiciera al gobierno superior el comandante de armas Domingo García, junto al diputado por Tucumán Manuel Felipe Molina y Cornelio Saavedra por su valiosa actuación. Tucumán, 12 de octubre de 1811. Archivo General de la Nación Argentina (AGN), sala X.

8 El gobernador Domingo García al Cabildo de Tucumán y Miguel Peñalba al cabildo de Tucumán, 19 de agosto de 1812, Archivo Histórico de Tucumán (AHT), Sección Administrativa, vol. 22. fjs. 304, 304 y 305. 
La participación de los sectores populares en la guerra revolucionaria y su vínculo con la política. Tucumán en 1815

naturales e hijos de esta jurisdicción". Gregorio Aráoz de Lamadrid (1947), militar tucumano veterano de las guerras de independencia, recordaba la iniciativa fundamental de Bernabé Aráoz y su tío, el cura Pedro Miguel Aráoz, en la reunión de "2000 hombres decididos". Aunque exageraba el número, no erró al mencionar que instruidos por Balcarce, "fueron armados... de lanzas y aun de cuchillos que colocaban amarrados en lugar de moharras" (p. 25). Su acción en la batalla fue señalada por Francisco Javier Mendizábal (1997) con bastante detalle de la acción: eran "seiscientos de paisanaje armados de lanzas, espadas y machetes" que cargaron detrás de doscientos cazadores con fusil (p. 46). Rechazado el enemigo, el heroísmo demostrado "por los paisanos que nunca se habían hallado en acciones de guerra" fue resaltado por Belgrano (Páez de la Torre, 1987, p. 199). . Luego de la victoria del 24 de septiembre de 1812 , en febrero del año siguiente participaron de la batalla de Salta los "escuadrones de dragones de la milicia patriótica" de Tucumán liderados por Bernabé Aráoz (Museo Mitre, 1914, p. 362). Siendo alcalde de primer voto de la ciudad, Aráoz creó en octubre de 1813 un cuerpo de dragones en Tucumán para apoyar al ejército auxiliar (Páez de la Torre y Bascary de Peña, 2012, p. 56).

Por lo dicho, podemos afirmar con Davio que los tucumanos no fueron en absoluto ajenos al proceso de militarización y aportaron contingentes de milicianos en repetidas ocasiones. Así, si inicialmente las milicias constituían cuerpos de reserva y precisamente por ello no eran regulares en el tiempo, en Tucumán se tornaron permanentes ante las urgencias de la guerra. Aunque esas levas no fueron masivas

9 Mendizábal era ingeniero militar. Aunque no participó de la batalla de Tucumán, se ocupó de dibujar los planos de las batallas más importantes de la guerra en los Andes centro meridionales sobre la base de relatos de testigos presenciales del ejército de Lima. 
(López, 2010). Cuando el norte del Virreinato del Río de la Plata, incluidas las "provincias de arriba" anexadas por el virrey de Lima, se convirtió en escenario de la disputa entre dos polos de poder americano, Buenos Aires y Lima, los pueblos sufrieron una guerra que alteró la vida cotidiana de las comunidades locales y sus habitantes. La victoria de septiembre de 1812 fue un evento bélico clave, ya que estableció el frente norte de la guerra con el ejército enviado desde el Perú. Para los tucumanos, fue la primera y única vez que la guerra revolucionaria tuvo por escenario a esa jurisdicción. En esa acción, tuvieron un rol capital los sectores populares de la ciudad y de la campaña, como señala Davio (2018). Casi dos meses después, los habitantes rurales fueron convocados para refrendar una decisión tomada en la ciudad: la elección de los diputados a la Asamblea General Constituyente que inició sus sesiones el 31 de enero de 1813 (Tío Vallejo, 2001; Abbate, Davio y Espíndola, 2013, Lupiańez, 2016).

Hacia 1815, según el cálculo de fuerzas milicianas realizado por Bernabé Aráoz, "existían 1725 individuos distribuidos en forma equitativa en las localidades rurales de Río Seco, Nogales y Timbó, Potrero Grande, Simoca, ciudad capital, Chicligasta, Monteros, Garcías, Burruyacu, Costillas, Río Chico, Juárez, Ticucho, Lules y Río Grande" (Davio, 2009, p. 94). ${ }^{10}$ Parolo y Macías entienden que a lo largo de la década revolucionaria el "servicio de armas en Tucumán fue un requerimiento que se extendió para todos los "habitantes" de la jurisdicción" con el fin de nutrir al Ejército Auxiliar del Perú. Esto involucró básicamente los sectores populares (Macías y Parolo, 2010; Mata, 2008). Se produjo así la militarización de la ciudad y del ámbito rural tucumano.

10 Carta de Bernabé Aráoz al Poder Ejecutivo. Aunque la autora no indica el ańo, es probable que fuera 1815 . 
La participación de los sectores populares en la guerra revolucionaria y su vínculo con la política. Tucumán en 1815

\section{La participación popular y las "facciones". El cabildo y el gobernador}

El establecimiento de la Junta Provisional Gubernativa en Buenos Aires el 25 de mayo de 1810 dio inicio a la revolución en el espacio rioplatense. Los cabildos, centro de la vida política en las ciudades hispanas, fueron interpelados como representantes de los pueblos ante la ausencia del monarca. Fueron cabildos abiertos los que eligieron a los primeros diputados para las juntas que representaron a los pueblos. Luego de esas primeras experiencias electorales, la historiografía ha destacado la temprana adopción del sistema representativo a través del sistema de sufragio indirecto e individual introducido por el Reglamento de 1811 para la elección de autoridades locales y provinciales (Chiaramonte, 1995). Las controversias que desató esa medida entre los cabildos conformados según el uso y la costumbre (de base jerárquica y corporativa) y las nuevas autoridades elegidas por ese modo inédito revelaron las perplejidades que instaló la revolución en la vida política, pues diversas instituciones se disputaron la invocación del pueblo. Esas elecciones, como nueva forma de expresión de la voluntad pública, entró en competencia con la representación de la comunidad monopolizada por el cabildo.

En 1814, la elevación de la ciudad al rango de cabecera de una nueva provincia modificó el juego político que el cabildo había logrado mantener sobre las autoridades locales delegadas del poder central. El agrupamiento político liderado por Bernabé Aráoz capitalizó los méritos de la victoria en la batalla de septiembre de 1812 y la exitosa movilización de la campańa para resistir al ejército enemigo. Designado como gobernador de la provincia, Aráoz reforzó sus vínculos con el gobierno superior. El sector contrario se fortaleció en el control del cabildo. A partir de entonces, se manifestó la tensión entre ambos agrupamientos políticos, uno conducido 
por Bernabé Aráoz y nutrido especialmente con miembros de su parentela, y otro, cuyo referente o principal vocero fue el exgobernador Domingo García, que reunió a otro conjunto de notables (Abbate, 2016).

No se trataba de las primeras "facciones" en la historia local ni tampoco de las últimas. Las tensiones políticas entre los sectores de las élite formaban parte de la dinámica del ejercicio de las funciones capitulares. A fines del siglo XVIII, por ejemplo, se destacaron las que agruparon a jesuitas y antijesuitas con motivo de la expulsión de la Compañía de Jesús y la administración posterior de sus bienes (García Calderón, 2009; Leoni Pinto, 1996; Saltor, 2003; López, 2013). Asimismo, otros agrupamientos se hicieron visibles a partir de la revolución (Nanni, 2017). En el marco de las disputas entre "facciones", no era extraño que el sector minoritario de la dirigencia capitular apelara a una "representación" o petitorio popular para contestar en nombre del "pueblo" las decisiones del sector mayoritario o prevalente en la institución (Morgan, 2006, p. 178). Esas experiencias políticas se manifestaron sin solución de continuidad en la etapa revolucionaria; sin embargo, la invocación del pueblo tuvo, entonces, una potente novedad: se trataba del pueblo soberano (Verdó, 2002, p. 396).

La historiografía rioplatense ha apelado al concepto de "facciones" para referirse a los agrupamientos políticos que asumieron el protagonismo en la primera mitad del siglo XIX, especialmente luego de la primera década de la revolución cuando los sucesivos fracasos de gobierno quebraron la legitimidad de la dirigencia que había tomado el relevo de la autoridad virreinal. No obstante, la presencia y acción de esos grupos se percibió a lo largo de toda la historia. El uso del término ha merecido reparos, aunque continúa utilizándose para englobar una serie de experiencias políticas más o menos diversas, que comportan variadas dimensiones. Entre 
La participación de los sectores populares en la guerra revolucionaria y su vínculo con la política. Tucumán en 1815

ellas, la politización de los sectores populares, la circulación de múltiples lenguajes políticos en el interior de sus entramados, su vinculación con el fenómeno de la guerra, etc., como han señalado Ignacio Zubizarreta y Mario Etchechury Barrera (2014, p. 11). Sin embargo, la idea que unifica todas esas experiencias es la tensión entre la unidad y la pluralidad en el terreno de la vida política decimonónica. La denominación "facción" o "partido" a un agrupamiento político tenía un sentido peyorativo porque se contraponía al ideal de unidad que se asociaba a la salud del cuerpo político (Palti, 2007).

Entre las características de las facciones suelen mencionarse diversos grados de cohesión ideológica y social, cierta permanencia de fidelidades y lealtades internas y diversos grados de legitimidad en el ámbito de la opinión pública. En muchos casos, podrían caracterizarse como coaliciones político-militares construidas alrededor de liderazgos civiles o jefaturas militares distribuidos en un amplio arco geográfico. En su interior convergían intereses a menudo circunstanciales cuando no contrapuestos. En otros casos, se observa la presencia de discursos o núcleos identificadores permanentes que terminan por dar sustento a lo que en el léxico de la época se solía denominar "causas".

Por otra parte, no se puede desconocer que en la disputa política manifestada entre agrupamientos políticos continuaban teniendo peso propio las "redes de poder", como formas de solidaridad familiar (parientes, alianzas matrimoniales, compadrazgo) o clientelismo (amistad, colaboración económica) de redes personales horizontales y verticales que conectaban a comerciantes, magistrados y burocracia general con agentes y dependientes, que organizaban cadenas de mando político y militar (López, 2005). De ese modo, ligados a redes amplias de adscripción corporativa, los sectores dependientes solían asociarse con intermediarios que actuaban en procesos de comunicación, información y adhesión, como curas rurales y 
jefes militares que hacían promesas y daban garantías (Davio, 2018, p. 47). Desde su posición social, dialogaban (negociando, resistiendo o rebelándose) con los sectores de poder, cualesquiera que fuese su rol en ese ordenamiento político.

\section{La soberanía popular entre "milicias y paisanos suel- tos”. Tucumán, junio de 1815}

El 3 de abril de 1815, un pronunciamiento militar en Fontezuelas (Buenos Aires), desató una anunciada crisis política en los territorios rioplatenses. Ante el riesgo de acefalía, el cabildo porteño dispuso la deposición y reemplazo del director supremo que había regido el poder ejecutivo desde enero de ese año, así como la disolución de la Asamblea General Constituyente reunida desde 1813. Por otra parte, creó una Junta de Observación encargada de la convocatoria a un nuevo congreso para que dirima la organización de los pueblos y dictó un Estatuto provisional para la dirección y administración del Estado el 5 de mayo de 1815. Esa normativa incluía una serie de novedades legales profundas e introdujo el principio de soberanía popular para la elección de autoridades. Consideraba que la selección del director, pasando por gobernadores y capitulares así como los representantes al Congreso Constituyente, debía realizarse por medio de elecciones indirectas con participación popular en la ciudad y en el ámbito rural. De esa manera, gran parte de los habitantes de los "pueblos" y comunidades políticas de naturaleza corporativa-territorial se convertían en ciudadanos en igualdad de condición legal y se desechaban antiguas jerarquías y adscripciones sociales (Ravignani, 1937). ${ }^{11}$ Recibidas las novedades de Buenos Aires, el gobernador de la nueva provincia de Tucumán, Bernabé Aráoz, coronel del Regimiento de Dragones de Milicias Regladas de Tucumán y coronel mayor

11 Estatuto provisional para la dirección y administración del Estado, dado por la Junta de Observación el 5 de mayo de 1815, sección primera, cap. IV. 
La participación de los sectores populares en la guerra revolucionaria y su vínculo con la política. Tucumán en 1815

de los Ejércitos de la Patria, manifestó la aceptación de las novedades por parte del pueblo tucumano. ${ }^{12}$

En tanto, el cabildo tucumano, si bien reconocía al nuevo director supremo consideraba que se debía consultar a la comunidad local, "oír al pueblo [cursiva añadida] para que él mismo lo sancionara libremente bajo las modificaciones y reformas que estimara convenientes" (Correa Luna, 1917, p. 51). ${ }^{13}$ El cabildo decidió formar una junta para que estudie el estatuto, a la vez que aclaraba que eso no era óbice para mantener lazos de unión con el resto de los pueblos y con las autoridades superiores. La decisión de discutir el estatuto con una representación ampliada respecto de lo que pudiera ser un cabildo abierto replicaba lo realizado poco antes en la ciudad de Salta. Allí, nueve representantes nombrados electoralmente habían conformado junto al cabildo una reunión que propuso modificaciones al estatuto, jurándolo en julio de ese año (Marchionni, 1999). Algo similar ocurrió en la ciudad de Jujuy, donde se agregaron enmiendas al texto estatutario que limitaban el poder del gobernador de la provincia de Salta respecto a la tradicional jurisdicción del cabildo jujeño (Rojas, 1913).

Según lo previsto, el 22 de junio se realizaron elecciones para nombrar diputados. El cabildo preveía la inclusión de los "vecinos" del ámbito rural y los invitó a incorporarse a los cuarteles de la ciudad (Lizondo Borda, 1939). ${ }^{14}$ Los "sujetos escasos", a los que alude la convocatoria eran aquellos de "calidad", es decir, "vecinos" en sentido tradicional y no los nuevos "ciudadanos" propuestos por el estatuto sujeto a

12 Un análisis estrictamente político de los términos de la disputa entre el cabildo y el gobernador en la coyuntura de junio de 1815 en Tucumán se encuentra en Lupiañez (2016, pp. 27-52)

13 Oficio del cabildo de Tucumán al de Buenos Aires, 1 de junio de 1815.

14 Acta del Cabildo del 12 de junio de 1815. 
debate. El mismo día de la elección, Aráoz se quejó por la inconsulta actuación capitular y recordó al cabildo que era él, en tanto autoridad gubernativa, quien debía liderar la iniciativa de sanción (eludiendo la posibilidad de discusión) del estatuto. ${ }^{15}$ Sin embargo, una vez nombrados los diputados, el gobernador dio su "consentimiento y aprobación" a lo realizado, pero tuvo dos objeciones. La primera fue la selección del sargento mayor graduado Tomás Alurralde, ayudante de plaza. El gobernador obviaba mencionar que el 20 de junio había ordenado a Alurralde que saliera de la ciudad con rumbo a la villa de Trancas donde recibiría órdenes. Alurralde se excusó del encargo. Dos días después, el gobernador le inició un sumario acusándolo de solicitar sufragios a los "ciudadanos" para ser nombrado elector. ${ }^{16}$ La segunda objeción fue que la aprobación de las elecciones era realizada "sin perjuicio asimismo de los derechos que pertenecen a los vecinos de la jurisdicción, que no han concurrido" (Lizondo Borda, 1939). ${ }^{17}$ Esto es, el gobernador se erigió en garante de la fracción de la comunidad que no había tenido parte en la elección. Atento a esa situación, el 23 de junio el cabildo envió una circular a los alcaldes de campaña para que se votara allí. Incluso, el 24 de junio se dirigió al alcalde de Los Juárez y ordenó que la elección no se hiciera en casa del cura párroco "para no molestarlo" informando cambio del lugar de elección. Mientras el alcalde de primer voto Domingo García ordenaba al alcalde de Los Juárez la reunión de los vecinos del curato en nombre de los "diputados de este Pueblo", Aráoz movilizaba gente en el ámbito rural”. Para algunos, el gobernador era el responsable de que no votaran los vecinos

15 Bernabé Aráoz al cabildo de Tucumán, Tucumán 22 de junio de 1815, en AHT, S.A. 24, fjs. 155-156.

16 El gobernador Aráoz al ayudante de Plaza José Tomás Alurralde, Tucumán 20 de junio; Alurralde al gobernador, Tucumán 20 de junio; Sumario a José Tomás Alurralde, Tucumán 22 de junio, en AGN. X 5-10-3.

17 Acta del Cabildo del 21 de junio de 1815. 
La participación de los sectores populares en la guerra revolucionaria y su vínculo con la política. Tucumán en 1815

de la campaña en la ciudad pues, "el gobernador... despachó órdenes para que las milicias y los paisanos sueltos se unieran en la Ciudadela"18, lo que dio pie a un nuevo capítulo en la disputa entre agrupamientos locales.

Es probable que los intentos de eludir a algunos agentes, como al comandante Alurralde - por parte de Aráoz- o al cura de los Juárez - por parte del cabildo- se fundara en la conocida adscripción de los mismos a algunos de los agrupamientos en pugna y a la previsible capacidad de movilización que, en calidad de intermediarios, suponía su rol activo en los escenarios electorales. El 22 de junio, mientras en la ciudad se realizaban los comicios, unos diecisiete "vecinos de la vasta campaña" (sic) dirigían una representación al director supremo en la que suplicaban que se conservara como gobernador a Aráoz ante los rumores de su deposición acusando a un grupo que no llegaba a doce individuos. Por su parte, Aráoz se dirigió reservadamente al director supremo y denunció que "ocho diputados nombrados por el pueblo para reconocer el Estatuto se dirigen al proyecto de constituirse soberanos independientes de esta capital". ${ }^{19}$ Las acusaciones expresaban los temores reales o imaginarios del gobernador. Aráoz llevaba tan solo siete meses en el gobierno de una nueva provincia creada por un poder superior, que no se había recuperado del todo de una crisis de autoridad profunda. Asimismo, a sus espaldas, Aráoz tenía la amenaza del gobernador de Salta quien, enfrentado con el director supremo procuraba construir su propio espacio de poder.

El 30 de junio de 1815, una "asamblea popular", según la apreciación peyorativa del cura José Agustín Molina, se con-

18 Nicolás Laguna al Director Supremo, Tucumán, julio de 1815 (AGN. X 5-10-3).

19 Representación de varios vecinos al Director Supremo, 22 de junio; El gobernador Aráoz al Director Supremo, 24 de junio (AGN.X 5-10-3). 
gregó en las inmediaciones de la ciudad de Tucumán para revocar las decisiones tomadas por el cabildo local. La reunión no se realizó en la plaza de armas, sino en el lugar donde había acontecido el episodio central de la victoria del 24 de septiembre de 1812. Se trataba de un sitio de fuertes connotaciones simbólicas, el "campo de honor" vinculado a la guerra y a la adhesión tucumana a la revolución (García de Saltor, 2003). Según acuerda la historiografía local, a pesar de su ausencia física, la reunión fue obra intelectual de Bernabé Aráoz (Lizondo Borda, 1948; Páez de la Torre, 1987).

En el sitio referido se encontraban "Congregados los habitantes de su Campaña [de Tucumán] que componen seis partidos e incorporándose a nosotros una parte considerable y sana de la Ciudad" (Lizondo Borda, 1939, p. 270). ${ }^{20}$ Las firmas recogidas sumaban alrededor de ciento cincuenta y siete, cifra reducida respecto de las más de cuatro mil almas que decía el acta haber reunido. San Miguel de Tucumán, como todas las ciudades occidentales de la época preindustrial, tenía una población rural sensiblemente mayor que la urbana. Incluso, el territorio tucumano habría sido de los más densamente poblados del Río de la Plata. Los cálculos para la época proponen unos cuatro mil habitantes para la ciudad, a los que se le sumarían unos dieciséis mil de su jurisdicción de campańa, es decir, cerca de veinte mil individuos (Parolo (2003); Pucci, (1999, p. 16); Gil Montero (1999); Aráoz (1995); Aráoz (1996). La mayoría de los presentes en el sitio eran milicianos de zonas rurales. Se sabe que el número de enrolados en las milicias fue alto durante toda la década revolucionaria. La estimación de Nicolás Laguna, uno de los diputados elegidos el 22 de junio, evaluaba la cantidad de

20 Acta del cabildo, 30 de junio de 1815. El documento original se encuentra en el Archivo Histórico de Tucumán (AHT). En 1939 se publicó en el volumen I de la compilación de Manuel Lizondo Borda, que reunió las actas del Cabildo de Tucumán entre 1810 y 1824 (1939, pp. 270-278) 
La participación de los sectores populares en la guerra revolucionaria y su vínculo con la política. Tucumán en 1815

los presentes en unos "500 a 1000 hombres todos armados" (Bazán, 1986, p. 171). ${ }^{21}$ Si bien el número era sensiblemente menor en ese cálculo, no dejaba de representar una cifra respetable.

En la composición de la asamblea es posible reconocer una primera línea de "cabecillas": once capitanes que habrían llevado a sus tropas, ${ }^{22}$ que firmaron por sí y a nombre de sus escuadrones o compañías. Si estimamos la composición de las compañías en cien hombres y la de los escuadrones en trescientos, según el reglamento de milicias de 1801 que se tomaría como referente para organizarlas, ${ }^{23}$ la cifra que calculaba Laguna resultaría bastante aproximada. Por otro lado, dos curas de campaña firmaron también a nombre de sus feligresías $^{24}$ con lo que el número final resulta importante, aunque impreciso a la vez que alejado del cálculo de los cuatro mil que considera el acta. Más aún, si se comparan estas cifras con el número de votantes en las "elecciones populares" indirectas del periodo 1811-1816. Las elecciones de diputados de mayo de 1816 al Congreso que declaró la independencia de las provincias en América del Sur fueron las

21 Nicolás Laguna al Director Supremo, Tucumán 3 de julio de 1815.

22 Cayetano Aráoz, Gerónimo Zelarayán, Francisco Bruno de San Martín, Javier Norri, Gerónimo Núñez, José Alejandro Carrasco, Miguel Soto, Toribio Calvo, Pedro Antonio García, Miguel Peñalba, Pedro José Velarde. Acta del 30 de junio de 1813. A partir del acta de 1815 se construyó una base de datos que rastrea los puestos militares y civiles de los participantes en la asamblea sobre la base de diversas fuentes. Esta base registrada en forma de cuadro no fue incorporada en este trabajo por falta de espacio.

23 Marisa Davio cita la respuesta del Director Supremo a Bernabé Aráoz sobre la organización de las milicias y su indicación acerca de la reglamentación de referencia que continuaba siendo el Real reglamento de milicias de 1801 (Davio, 2009, pp. 95-96)

24 Maestro Luis Antonio Aráoz del partido de los Juárez y Gregorio Villafañe, cura de Burruyacu. Acta del 30 de junio de 1815. 
de mayor participación, con un promedio de cien votantes por cada uno de los seis curatos de la campaña tucumana (Lupiañez, 2017).

Una segunda línea de referentes estaba conformada por individuos notables que acompañaron el movimiento, entre ellos se reconocen algunos miembros del cabildo en años anteriores (Juan Bautista Paz, Juan Josef de La Madrid, Francisco B. Aguirre), dos alcaldes de partido o de hermandad (Bernardino de Medina y Bernardino Acosta) y, principalmente, los militares con los grados de capitán, teniente, alférez y ayudante mayor que votaron individualmente. Se destacan también dos sacerdotes importantes, el cura rector de la iglesia matriz y el vicario foráneo. ${ }^{25}$

El tercer nivel estaría conformado por los sargentos (Pedro Tirado, Hilario Sardina y Martín Âlvarez) y por individuos que no registran graduación militar ni hemos logrado identificarlos entre los notables más reconocidos. ¿Serían estos, los "paisanos sueltos" mencionados en el documento? ¿Son los mismos actores que la historiografía identifica junto a las familias campesinas de "pequeńos productores, con algún tipo de acceso a la tierra, en el paisaje complejo de la sociedad rural" (López, 2014, p. 321)? ¿Se trata de sujetos con un estatus semejante a los "paisanos itinerantes" (Salvatore, 2018 y 2020) del ámbito rural pampeano de décadas posteriores? Es posible que se trate de actores que contrastan con las milicias rurales no solo por no estar en servicio de armas, sino también por su menor arraigo (vecindad) en la sociedad local.

Lo que resulta indudable es la preponderancia del elemento militar de la asamblea, advertida por los mismos contemporáneos y su carácter visiblemente masculino. La condición

25 Pedro Miguel Aráoz, cura de la iglesia matriz y Francisco Borja Aguilar, vicario foráneo. Acta del 30 de junio de 1815. 
La participación de los sectores populares en la guerra revolucionaria y su vínculo con la política. Tucumán en 1815

militar de los presentes no puede dejar de relacionarse con la figura del gobernador y los títulos militares que ostentaba. A pesar de que tanto los asistentes como sus críticos adscribían a sus integrantes al ámbito de la campaña, no podemos identificarlos en los registros según sus ocupaciones en el mundo rural, esto es, como labradores, arrieros, arrendatarios, peones de campo o pequeños productores independientes. ${ }^{26}$ Por otro lado, más allá de la notabilidad de varios participantes, el acta no los consigna con el tratamiento de "don". Esa condición está prácticamente omitida en el registro los firmantes; prefirieron destacar los grados militares y en algunos casos -los menos-, el título de "doctor" o "maestro".

Los participantes militares corresponden a los grados de capitán (diecisiete), teniente (catorce), alférez (once), ayudantes mayores (dos) y sargentos (tres). Se trataría de cuerpos milicianos en su mayoría porque la presencia de jefes militares "de ejército" está discriminada en pocos casos (Teniente de Ejército, Eusebio Caínzo; Capitán de Ejército, Josef Manuel Lugones). Algunos de ellos, con grados de capitán en compañías y escuadrones de dragones (Miguel G. Zelarayán, Miguel Soto, Miguel Peñalba, Francisco Xavier Norry) del que era, como ya se dijo, coronel el gobernador Aráoz, habían firmado la referida representación presentada el 22 de junio en defensa del gobernador.

Respecto de los oficiales, Tío Vallejo (2001) sostiene que:

"Pareciera que la carrera más común ha sido la de vecinos jóvenes alistados como soldados en los regimientos de 1810 pero cuya condición de soldados debe considerarse con cuidado porque eran todos "dones" reclutados en un cuerpo formado exclu-

26 Se trata de grupos, cuyos contornos son imprecisos también en fuentes censales, aunque los estudios de Cristina López estiman que alcanzaban la mayor parte de los padrones (López, 2014, p. 321) 
sivamente por vecinos. De estos jóvenes los que siguieron en el ejército los primeros años de la guerra, los más duros, y sobre todo aquellos que participaron en la batalla de Tucumán fueron nombrados alférez en 1813 para ser tenientes en 1815. Algunos ascendieron al grado de capitán en 1813; estos capitanes que se vieron favorecidos por la victoria en la batalla de Tucumán son los integrantes de las distintas facciones que veremos actuar después de 1819”. (p. 263).

En nuestro análisis, algunos de ellos aparecen ya en 1815 como parte del agrupamiento político que respondía al gobernador Aráoz.

Los eclesiásticos involucrados fueron cuatro: dos curas de partidos de campaña, el de Los Juárez, Maestro Luis Antonio Aráoz; el cura de Burruyacú Gregorio Villafañe, el cura rector de la Matriz Pedro Miguel Aráoz y el vicario foráneo Dr. Francisco Borja Aguilar. Precisamente, el primero de ellos, el cura de Los Juárez había sido evitado por los capitulares a la hora de realizar la elección en la campaña. La presencia de miembros del cabildo o de alcaldes de partido fue muy escasa. Se constata la presencia del alcalde de Hermandad de Chicligasta y de Bernardino Acosta, quien fue registrado con su grado militar, pero había sido elegido alcalde de los Juárez en ese año. Por otra parte, esos jefes militares y religiosos asumieron la representación de modo corporativo y jerárquico, pues dieron cuenta a través de sus votos y firmas la presencia de otros sujetos que se les subordinaban.

Considerando la composición de la asamblea en relación con los vínculos de parentesco o amistad entre los asistentes, la información con que contamos nos permite destacar el carácter articulador de la parentela del gobernador Bernabé Aráoz. En primer lugar, se identifican quienes tienen su mismo apellido, como sus tíos los curas Pedro Miguel y Luis Antonio; y sus primos, el capitán Cayetano y el teniente Ángel Benedicto. Se destaca también la presencia de su suegro, 
La participación de los sectores populares en la guerra revolucionaria y su vínculo con la política. Tucumán en 1815

Pedro José Velarde, diputado del comercio y capitán. Otros asistentes también tienen el mismo apellido: Miguel Aráoz, que bien podría ser su tío (hermano de Luis Antonio y de Pedro) o su primo (hermano de Cayetano y de Ángel Benedicto). En cuanto a Benito Aráoz, no hemos podido establecer su filiación. Se observa, no obstante, que el parentesco vincula a varios sujetos a quienes hemos considerado entre los "cabecillas". Pedro Miguel; Borja Aráoz y Cayetano Aráoz junto a Bautista Paz eran mencionados por sus detractores como "agentes de la tramoya" e integrantes de un "acuerdo cívico militar". ${ }^{27}$

En cuanto a la justificación de la asamblea, se planteó como un conflicto en términos de defensa de los "sagrados derechos de todo ciudadano" frente a "un corto número de individuos facciosos [que] perturban la inalterable quietud" de los tucumanos, aludiendo muy probablemente a los ocho miembros electos el 22 de junio y el cabildo. En el acta se aludía al "ciudadano" en el sentido dado por el estatuto - "cada ciudadano es miembro de la Soberanía del Pueblo" y "En esta virtud tiene voto activo y pasivo" - ${ }^{28}$ ergo, en el sentido de partícipe de una concepción de la soberanía única. En ese esquema, por otra parte, el número de cuatro mil participantes tenía peso propio.

La asamblea reafirmó los vínculos con Buenos Aires en coincidencia con la posición del gobernador y anuló la elección de representantes o "diputados" del 22 de junio, con el argumento de la solicitud de sufragios y la deficiente participación de los habitantes rurales. Asimismo, confirmó la vigen-

27 Nicolás Laguna al Director Supremo, Tucumán julio de 1815, AGN. X 5-10-3.

28 "Prerrogativas del Ciudadano", Estatuto provisional para la dirección y administración del Estado, dado por la Junta de Observación (05 de mayo de 1815), Sección I, Capítulo IV. ACA. 
cia del estatuto, eligió diputados al congreso soberano que se reuniría en 1816 e hizo lo propio con el gobernador Bernabé Aráoz. La asamblea replicó el modo de elección del gobernador de Salta, Martín Miguel de Güemes dos meses atrás.

En tanto sus críticos, los notables locales, no perdieron oportunidad de descalificarla y se refirieron a ella como "junta tumultuaria" (Furlong, 1960, pp. 181-182) 29 $^{29}$ "comicio militar y no cívico donde firmaron el acta los oficiales a nombre de los soldados" (Bazán, 1986, p. 171). ${ }^{30}$ Además, dejaron en claro que por detrás de eso se desarrollaba una lucha "facciosa" y señalaron que "los pretendientes a ser tenidos y reconocidos por Diputados de Tucumán, no los quiere la ciudad; pero los quiere el partido que prevaleció con la fuerza y manejos en la gente de esta jurisdicción" (Furlong, 1960, pp. 181-182) ${ }^{31}$. Fray Cayetano Rodríguez, en sus cartas al cura José Agustín Molina, alineado al grupo opositor al del gobernador, opinaba críticamente de la "facción tucumanoheroína"32, los "aráoces"33 o los "héroes" (Rodríguez, 2008, pp. 138 y 149). Esos apelativos permiten observar la asociación simbólica que pretendía ese sector con la batalla del 24 de septiembre de 1812. Acontecimiento que significó el encumbramiento del grupo en detrimento del sector que lideraba el que fuera gobernador de la antigua provincia de Salta a la que había pertenecido Tucumán hasta 1814, Domingo García (Abbate, 2016).

29 Carta de Diego León de Villafañe a Ambrosio Funes, Tucumán, 25 de enero de 1816.

30 Nicolás Laguna al Director Supremo, Tucumán 3 de julio de 1815.

31 Carta de Diego León de Villafañe a Ambrosio Funes, Tucumán, 25 de enero de 1816

32 Carta de Fray Cayetano Rodríguez a Agustín Molina, Buenos Aires, 10 de octubre de 1815.

33 Carta de Fray Cayetano Rodríguez a Agustín Molina, Buenos Aires, 18 de julio de 1815 . 
La participación de los sectores populares en la guerra revolucionaria y su vínculo con la política. Tucumán en 1815

Los opositores también reclamaban que los tres nombrados el 30 de junio lo habían sido "con facultades de deliberar sobre la suerte de aquel Pueblo [de Tucumán] con dependencia al gobierno para que en una sola familia se conserve la Soberanía”. ${ }^{34}$ Esto significaba que, por detrás de esas decisiones se hallaban nombres vinculados a la familia Aráoz, quienes concentraban la capacidad de tomar decisiones en nombre de la comunidad local. Sin embargo, la crítica no era exclusiva de los detractores del gobernador y su red parental. El mismo Aráoz se preocupó por separar lo que consideró un "cabildo abierto" o "pueblada" 35 de la condición de "tumulto".36

La forma que tomó la asamblea del 30 de junio en el Campo de las Carreras es similar a la que Fabián Herrero (2007) conceptualiza como "movimiento de pueblo" que, a diferencia de otros de su tipo, tuvo por finalidad confirmar la autoridad del gobernador y, por extensión, la del gobierno superior; no deponerlas. Las decisiones tomadas exigieron el concurso de los ausentes en el "Campo de las Carreras". Por ello, acto seguido, la asamblea de la Ciudadela "invitó" a los ausentes (cabildo y corporaciones) para sumar "sus votos con estos libremente y sin coacción” (Lizondo Borda, 1939, p. 271). ${ }^{37}$ Un cabildo abierto se reunió en la tarde de ese mismo 30 de junio. Quienes debatieron entre las tradicionales paredes capitulares fueron mencionados por aquellos que se

34 Los firmantes eran Nicolás Laguna; José Ramón Ledesma; José Tomas Alurralde; Domingo García y Manuel Bazán. Oficio de los diputados al Director Supremo. 9 de julio de 1815. AGN.X 5-10-3.

35 Fray Cayetano Rodríguez a José Agustín Molina, Buenos Aires, 18 de julio de 1815.

36 Expediente "Declaraciones sobre el orden que se supone haberse observado en las actas de la Ciudadela", 07 de Julio de 1815 (AGN.VII. Legajo 7. Documento 130).

37 Acta del 30 de junio de 1815. 
encontraban rodeando la casa capitular, como los "literatos", los "ilustrados". ${ }^{38}$ De hecho, muchos de los presentes en la sala capitular ostentaban títulos de doctor. Se persuadió a los presentes ratificar lo actuado horas antes (Lizondo Borda, 1939). ${ }^{39}$ Claro está que el gobernador estaba acompañado por los oficiales del Regimiento de Dragones de Caballería reglada. Todos estaban armados. En tanto, fuera del recinto capitular, se encontraba reunido el "pueblo" que se había trasladado desde las afueras de la ciudad hacia la plaza. La partida pareció ganada por el gobernador. La escena da a pensar que no había márgenes para discutir lo decidido en la Ciudadela.

Sin embargo, el sector contrario representado en el cabildo abierto no aceptó la imposición y apeló al Congreso de los pueblos en 1816 para rebatir la elección de los diputados "en odio a la forma tumultuosa" con que se efectuó. No dejó de achacarse al grupo de Aráoz el mote de "partido" ni de cuestionar los mecanismos de adhesión. El éxito del "partido" había sido prevalecer entre la gente del ámbito rural por "fuerza y manejos" (Furlong, 1960, p. 182). En ese sentido, los trabajos referidos a la década de 1820 registran acusaciones a los jefes de seducir a los sectores populares para conseguir que se sumen a sus contiendas políticas (Davio, 2018). Otros estudios sobre espacios diversos insisten también en la combinación de violencia y de seducción en la base de las relaciones clientelares (Hébrard, 2014, p. 137). En el caso que analizamos, es posible que otros factores como las lealtades por parentesco o entre compañeros de armas, compromisos concretos, estrategias individuales y colectivas incidieran en la movilización (Hébrard, 2014, pp. 274-278).

38 Expediente "Declaraciones sobre el orden que se supone haberse observado en las actas de la Ciudadela”, 7 de julio de 1815, AGN. Sala VII, Legajo. Documento 130.

39 Acuerdo del 30 de Junio de 1815 
La participación de los sectores populares en la guerra revolucionaria y su vínculo con la política. Tucumán en 1815

Asimismo, el principio de soberanía popular alentaba cierto igualitarismo en la medida que el miliciano se identificaba con el ciudadano.

Desde el otro lado, las voces que se alzaron en defensa de la asamblea popular procuraron diluir la calificación de la misma como tumulto, para ello apelaron como justificativo, además de las críticas circunstancias, a la necesidad de verificar la participación de la campaña en las elecciones que se habían llevado a cabo en la ciudad sin la concurrencia de los vecinos de la jurisdicción.

Amén de las condiciones de excepcionalidad que podrían justificar la reunión y su proyección en el cabildo abierto subsiguiente, se invocó como desencadenante un móvil político. Se procuró destacar el peso del número de los asistentes, pero evitar su catalogación como tumulto, al traducir la reunión como una experiencia de participación política compatible con la legitimidad republicana y el respeto por las autoridades vigentes. En ese sentido, el acta que se levantó aclaraba que los puntos que se sometieron a votación se habían "meditado y examinado con reflexión" y que con "la mayor complacencia y libertad" adherían a los mismos (Lizondo Borda, 1939, p. 217). ${ }^{40}$

Es notable la claridad con que se expresa en estas disputas el ideal de unidad en la vida política, al punto que quienes se oponen al gobernador no se perciben como una contraparte, 50 sino como la "ciudad", esto es, como la totalidad de la comunidad representada en el cabildo. De ese modo, mientras los capitulares pretendían encarnar el interés común de la república, quienes seguían al gobernador solo representarían los intereses de una parte de ella, un "partido". Al mismo tiempo, ese contraste revela una composición predominan-

40 Acta del 30 de junio de 1815. 
temente rural del agrupamiento de Aráoz. En ese contexto, el uso del término "partido", si bien permitió identificar diferentes posiciones, no supuso permanencia o cristalización institucional, mucho menos una asociación para promover candidaturas (Sábato y Ternavasio, 2011, p. 92)

Experiencias de movilización política como esta fueron más frecuentes en la década siguiente al calor de la competencia entre diversos sectores de la élite por el gobierno local. En ese sentido, esa asamblea inauguró una nueva forma de construcción de relaciones con lo político por parte de los sectores populares.

\section{Conclusiones}

San Miguel de Tucumán, ciudad situada a medio camino entre las minas de Potosí y el puerto de Buenos Aires, experimentó la guerra de independencia de manera directa al convertirse por única vez en campo de batalla el 24 de septiembre de 1812. En ese momento, los sectores populares rurales se hicieron visibles, según constata Davio. En medio de esos acontecimientos, el gobernador Bernabé Aráoz desarrolló su carrera militar y política.

La reunión multitudinaria del 30 de junio de 1815 en Tucumán se produjo en el contexto de crisis política general rioplatense; sin embargo, no se trató de una sublevación o movimiento conspirativo. El movimiento fue efecto de la competencia por el control del poder político local entre dos instituciones: una de origen tradicional y corporativa, el cabildo, y la otra de origen revolucionario, el gobernador nombrado por el cuestionado gobierno superior. En torno a ellas se alinearon dos agrupamientos locales. No era la primera vez que ocurrían disputas en la ciudad, pues eran parte de la dinámica de toda república tradicional. Sin embargo, en el contexto creado por la revolución y su contracara, la guerra, la novedad fue que ambos contendientes debieron apelar 
La participación de los sectores populares en la guerra revolucionaria y su vínculo con la política. Tucumán en 1815

a la noción de soberanía popular y le dieron encarnadura material. Para ello, hubo que relajar la tradicional jerarquía espacial entre campo y ciudad (y también la jerarquía social, que permitía a gente de calidad mezclarse con las otras gentes) en la elección del 22 de junio, pero sobre todo el 30 del mismo mes. El ganador, al menos de esa vuelta, fue aquel que pudo capitalizar el apoyo numéricamente mayoritario en tanto escenificaba mejor el principio de soberanía popular. En ese esquema, la cantidad legitimaba el acto. Sin embargo, la notabilidad complementó la fuerza del número con la calidad de sus participantes y la velada amenaza de las armas, y le dio un fundamento tradicional a ese nuevo modo de expresión política que echaba por tierra la exclusividad de la voz capitular en la representación del "pueblo", pero sostenía una lógica de redes sociales, cuyos integrantes eran miembros de corporaciones militares, clericales y administrativas.

El gobernador fue el beneficiario del apoyo de los sectores populares rurales y militarizados identificados por su cantidad, su condición miliciana, la no portación del apelativo de don y la presencia de intermediarios como curas y mandos medios militares (sargentos y cabos). Pero también reconocibles en un juego de oposiciones reflejadas en las fuentes entre "los ilustrados" o "la ciudad" y "las milicias y paisanos sueltos" movilizados por el "partido".

La motivación explícita que ostentaban fue, con el respaldo del estatuto, el cumplimiento de sus derechos como ciudadanos. Aunque no se descarta que otro tipo de negociación, incentivo o incluso amenaza estuviera en juego allí. La defensa de los derechos o la calidad de ciudadano no era una cuestión menor, puesto que igualaba al borrar las diferencias étnicas, ocupacionales y jurídicas que caracterizaban a los sectores populares. De ese modo, los habilitaba a compartir con la élite un espacio común que no era el de la vida cotidiana, sino el ámbito de toma de decisiones. Y en eso la guerra 
había hecho lo suyo, pues los reunidos en la Ciudadela no usaban voluntariamente el calificativo de "don", pero sí mencionan el cargo militar. En simultáneo, el orden jerárquico se mantenía en la mención de sujetos de calidad junto a la presencia de mandos intermedios, cuya posición también devenía de la guerra. Con todo, es interesante comprobar que la asamblea inauguró una participación popular en los asuntos políticos de la república con importante presencia militar y rural sobre la base de la soberanía popular, anterior a los registros de 1819 consignados en el espacio local (Tío Vallejo, 2001; Davio, 2018). Una última referencia dedicada a aquellos mencionados como "paisanos sueltos" abre interrogantes en torno a los modos de articulación de cada grupo con los liderazgos sociales y políticos de agentes intermediarios y del gobernador sobre los que deberemos profundizar.

Recibido: 15 octubre del 2020

Aprobado: 20 de abril del 2021

\section{Referencias bibliográficas}

Abbate, G.; Davio, M. y Espindola, A.

(2013) Revolución, guerra y representación política. En C. López (Dir.), Orden y conflictos. Tucumán, de la colonia a la organización nacional (pp. 57-111). Rosario: Prohistoria.

Abbate, G. (2016)

Entre la ciudad y el partido. Los dilemas de la representación tucumana en el congreso de 1816. En C. Folquer y E. Ábalo (Coords.), La independencia en Tucumán, historia y celebración. Lenguajes, prácticas politicas y actores de una ciudad en guerra (pp.19-32) [libro electrónico]. San Miguel de Tucumán: Universidad del Norte Santo Tomás de Aquino. 
La participación de los sectores populares en la guerra revolucionaria y su vínculo con la política. Tucumán en 1815

Aráoz de la Madrid, G.

Memorias del Gral. Gregorio Aráoz de Lamadrid. Buenos Aires: Biblioteca del Suboficial: Campo de Mayo.

Aráoz, M. F.

Evolución demográfica de Tucumán a través de sus censos 1810-1869. Revista de la Junta de Estudios Históricos, 7, 11-33.

Aráoz, M. F.

Evolución demográfica de Tucumán a través de sus censos 1810-1869 (II). Revista de la Junta de Estudios Históricos, 8, 11-27.

Bascary, A. M.

Familia y vida cotidiana. Tucumán a fines de la colonia. San Miguel de Tucumán: Universidad Pablo de Olavide de Sevilla, Facultad de Filosofía y Letras, Universidad Nacional de Tucumán.

Boixadós, R. y Farberman, J.

(2015) Las casas sobre el papel. Población, familia y comunidad en un padrón colonial. La Rioja, Gobernación del Tucumán (Virreinato del Perú) siglo XVIII. El Taller de la Historia, 7 (7), 169-212.

Calvente, E.

Transgresiones a las "divinas y humanas leyes". Limitaciones a la religiosidad local en San Miguel de Tucumán (1767-1807). Boletín Americanista, XLXI (78) Recuperado de http://revistes.ub.edu/index.php/ BoletinAmericanista/issue/view/2186

Cansanello, O. C.

De súbditos a ciudadanos. Los pobladores rurales bonaerenses entre el Antiguo Régimen y la modernidad. Boletin del Instituto de Historia Argentina y Americana Dr. Emilio Ravignani, Tercera Serie, 11. 
Cansanello, O. C.

(2008) Ciudadano/vecino. En N. Goldman (Ed.), Lenguaje y revolución. Conceptos politicos clave en el Río de la Plata, 1780-1850 (pp. 19-34) Buenos Aires: Prometeo Libros.

Chiaramonte, J. C.

(1995) Vieja y nueva representación. Las elecciones en Buenos Aires, 1810-1820. En A. Annino (Ed.), Historia de las elecciones en Iberoamérica, siglo XIX: De la formación del espacio politico nacional. Buenos Aires: Fondo de Cultura Económica.

Chiaramonte, J. C.

(1999) Ciudadanía, soberanía y representación en la génesis del Estado Argentino (c. 1810-1852). En H. Sábato (Coord.), Ciudadania politica y formación de las naciones. Perspectivas históricas de América Latina. México: Fondo de Cultura Económica, Fideicomiso de las Américas.

Correa Luna, C.

(1917) Antecedentes porteños del Congreso de Tucumán. Buenos Aires: Compañía Sud-Americana de Billetes de Banco.

Davio, M.

(2009) El proceso de militarización durante la Revolución. Tucumán, 1812-1819. En C. López (Comp.), Identidades, representación y poder entre el Antiguo Régimen y la revolución, Tucumán, 1750-1850 (pp. 83102). Rosario: Prohistoria.

Davio, M.

(2018) Morir por la patria: participación y militarización de los sectores populares en Tucumán, 1812-1854. Rosario: Prohistoria. 
La participación de los sectores populares en la guerra revolucionaria y su vínculo con la política. Tucumán en 1815

Di Meglio, G.

(2007) ¡Viva el bajo pueblo! La plebe urbana de Buenos Aires y la política entre la revolución de mayo y el rosismo. Buenos Aires: Prometeo.

Diaco, K.

(2002) Tucumán y sus milicias, 1801-1812. En Tucumán y su historia (pp. 29-40). Tucumán: Universidad Nacional de Tucumán, Departamento de Extensión.

Escanilla Huerta, S., Morán, D. y Silveira, A.

(2012) Plebe, sociabilidad y revolución. El Perú y el Río de la Plata en el contexto de las guerras de independencia. Lima: Grupo Gráfico del Piero.

Fradkin, R. (2008)

¿Y el pueblo dónde está? La dificultosa tarea de construir una historia popular de la revolución rioplatense. En ¿Y el pueblo dónde está? Contribuciones para una historia popular de la revolución de independencia en el Río de la Plata. Buenos Aires: Prometeo.

Fradkin, R. O.

(2009) Tradiciones militares coloniales. El Río de la Plata antes de la revolución. En Flavio Heinz (Comp.), Experiências nacionais, temas transversais: subsidios para uma história comparada da América Latina (pp. 74-126). São Leopoldo: Editora Oikos. Recuperado de https://historiapolitica.com/datos/biblioteca/fradkin.pdf

56 Ferreira, P.

(2016) Ciudadanos en armas. La experiencia de la milicia cívica en Montevideo 1815-1817. Claves. Revista de Historia (2), enero-junio, 9-45.

Furlong, G. (1960)

(Comp.). Diego León de Villafañe y sus cartas referentes a la revolución argentina. Boletín de la Academia Nacional de la Historia, XXXVII (31), 181-182. 
García Calderón, M. L.

(2009) Las disputas por el poder en San Miguel de Tucumán a partir de la expulsión de los jesuitas. En C. López (Comp.), Identidades, representación y poder entre el Antiguo Régimen y la revolución. Tucumán, 17501850 (pp. 17-43). Rosario: Prohistoria Ediciones.

García de Saltor, I.

(2003) La construcción del espacio politico, Tucumán en la primera mitad del siglo XIX. San Miguel de Tucumán: Universidad Nacional de Tucumán, Facultad de Filosofía y Letras.

Garriga, Carlos

(2006) Patrias criollas, plazas militares. Sobre la América de Carlos IV. En E. Martiré (Comp.), La América de Carlos IV (pp. 35-130). Buenos Aires: Instituto de Investigaciones de Historia del Derecho. Cuadernos de Investigación y Documentos.

Gil Montero, R.

Familia campesina andina. Entre la colonia y el nuevo Estado independiente en formación. (Tesis para optar por el grado de doctora). Universidad Nacional de Córdoba, Facultad de Filosofía y Humanidades: Córdoba.

Halperin Donghi, Tulio

(1994) Revolución y guerra. Formación de una elite politica dirigente en la Argentina criolla, Buenos Aires, Siglo XXI Editores.

Hébrard, V.

(2014)

Dinámicas de movilización y lógicas de socialización de lo político en el mundo rural venezolano, 1858-1859. Illes i Imperi, 17. Dossier: Facciones y grupos políticos en la Hispanoamérica del siglo XIX. Recuperado de https://raco.cat/index.php/IllesImperis/ article/view/299455/388914 
La participación de los sectores populares en la guerra revolucionaria y su vínculo con la política. Tucumán en 1815

Herzog, T.

(2000) La vecindad entre condición formal y negociación continua. Reflexiones en torno de las categorías sociales y redes personales. Anuario IEHS, 15, 123-133.

Larrouy, A. (Comp.).

(1910) Documentos del Archivo General de Tucumán. Invasiones inglesas y revolución, 1806-1807, 1810-1812. Buenos Aires: Comisión Nacional del Centenario, Imp. y Casa Ed. Juan A. Alsina.

Leoni Pinto, R.

(2007) Tucumán y la región noroeste, periodo 1810-1825. Tucumán: Academia Nacional de la Historia, Universidad Nacional de Tucumán.

Lizondo Borda, M. (Comp.).

(1939) Documentos tucumanos. Actas capitulares. I. 18101816. San Miguel de Tucumán: Instituto de Historia, Lingüística y Folklore, Departamento de Investigaciones Regionales, Universidad Nacional de Tucumán.

Lizondo Borda, $\mathrm{M}$.

(1948) Historia de Tucumán (s. XIX). Tucumán: Universidad Nacional de Tucumán.

López, C.

(2005) Redes familiares y poder en el Tucumán de comienzos de siglo XIX. En I. García de Saltor y C. López (Comps.). Representaciones, sociedad y politica en los pueblos de la República. Primera mitad del siglo XIX (pp. 11-25). San Miguel de Tucumán: Facultad de Filosofía y Letras, Universidad Nacional de Tucumán.

López, C.

(2010) Bernabé Aráoz. Los caudillos y la movilización de la plebe. En AAVV. Cuatro bicentenarios. 1810, 1812, 1814 y 1816. (pp. 85-108). San Miguel de Tucumán: Junta de Estudios Históricos. 
López, C.

(2003) Los dueños de la tierra. Economía, sociedad y poder en Tucumán (1770-1820). Tucumán: Universidad Nacional de Tucumán.

Lupiañez, G.P.

(2016) Autonomía y soberanía en los usos de la noción de "pueblo". Disputas políticas entre el gobernador y el cabildo en torno del Estatuto provisional en Tucumán en 1815. Prohistoria, XIX (26), 27-52. Recuperado de https://dialnet.unirioja.es/ejemplar/450404

Lupiañez, G. P.

(2017) Las elecciones de diputados por Tucumán al Congreso General Constituyente. Modos de participación del pueblo en 1816. En X Jornadas La Generación del Centenario y su Proyección en el Noroeste Argentino. Desde el Centenario hacia una Historia Integral del NOA. 1900-1950 (pp. 446-465). San Miguel de Tucumán: Fundación Miguel Lillo, Centro Cultural Rougés.

Lupiañez, G. P.

(2018) Soberanía y autonomía. Usos de la noción de pueblo en Tucumán (Virreinato del Río de la Plata), 18061807. Humanidades. Revista de la Universidad de Montevideo, 3, 101-123. http://revistas.um.edu.uy/ index.php/revistahumanidades.

Macías, F.

(2010) Milicias y ciudadanos. Tucumán en la década revolucionaria. En AAVV. Cuatro Bicentenarios. 1810, 1812, 1814 y 1816. 85-108. San Miguel de Tucumán: Junta de Estudios Históricos.

Macías, F. y Parolo, M. P.

(2010) Guerra de independencia y reordenamiento social. La militarización en el norte argentino (primera mitad del siglo XIX). Iberoamericana, X (37), 19-38. 
La participación de los sectores populares en la guerra revolucionaria y su vínculo con la política. Tucumán en 1815

Marchionni, M.

(1999) Una elite consolidada. El cabildo de Salta en tiempos de cambio. En S. Mata de López, Persistencias y cambios: Salta y el noroeste argentino. 1770-1840 (pp. 177-239). Rosario: Prohistoria y Manuel Suárez Eds.

Mata, S.

(2010) Paisanaje, insurrección y guerra de independencia. El conflicto social en Salta, 1814-1821. En R. Fradkin y J. Gelman, Desafios al orden. Politica y sociedades rurales durante la revolución de independencia. Rosario: Prohistoria.

Mendizábal, F. J.

Guerra de la América del Sur. Buenos Aires: Academia Nacional de la Historia. Biblioteca de Publicaciones Documentales.

Míguez, Eduardo

(2016) Presentación al Dossier independencia y ruralidad en el Rio de la Plata, Mundo Agrario, La Plata, Vol.17 (35).

Morán, D.

(2011) Historiografía de la revolución. La participación plebeya durante las guerras de independencia en el Perú y en el Río de la Plata. Nuevo Mundo. https://doi. org/10.4000/nuevomundo.61404

Morán, D. y Aguirre, María

(2013) La plebe en armas. La participación popular en las guerras de independencia. Lima: Fondo Ed. de la USB.

Morgan, E. S.

(2006) La invención del pueblo, El surgimiento de la soberania popular en Inglaterra y Estados Unidos. Buenos Aires: Siglo XXI Eds. 
Museo Mitre

(1914) Documentos del Archivo de Belgrano (t. V). Buenos Aires: Coni Hermanos.

Nanni, F.

(2017) Grupos políticos y facciones en la construcción de la provincia de Tucumán (1814-1841). Polhis, X (19). Recuperado de http://www.historiapolitica. com/2017/12/27/novedades-polhis-19

Páez de la Torre, C.

(1987) Historia de Tucumán. Buenos Aires: Plus Ultra.

Páez de la Torre, C. y Peña de Bascary, S.

(2012) Porteños, provincianos y extranjeros en la batalla de Tucumán. Buenos Aires: Emecé.

Palti, E.

(2007) El tiempo de la politica. El siglo XIX reconsiderado. Buenos Aires: Siglo XXI.

Parolo, M. P.

(2008) Ni súplicas, ni ruegos. Las estrategias de subsistencia de los sectores populares en Tucumán en la primera mitad del siglo XXI. Rosario: Prohistoria.

Parolo, P.

(2003) Estructura socio ocupacional y sectores populares en Tucumán. Primera mitad del siglo XIX. (Tesis para optar al grado de doctora). Universidad Nacional de Tucumán, Facultad de Filosofía y Letras, Tucumán.

Pucci, Roberto

(1999) La población y el auge azucarero en Tucumán. Breves Contribuciones del Instituto de Estudios Geográficos, 7, $7-44$. 
La participación de los sectores populares en la guerra revolucionaria y su vínculo con la política. Tucumán en 1815

Ravignani, Emilio

(1937) Asambleas constituyentes argentinas seguidas de los textos constitucionales, legislativos y pactos interprovinciales que organizaron políticamente la nación (I). Buenos Aires: Instituto de Investigaciones Históricas de la Facultad de Filosofía y Letras de la Universidad Nacional de Buenos Aires.

Ravinovich, A.

(2012)

La militarización del Río de la Plata, 1810-1820. Elementos cuantitativos y conceptuales para su análisis. Boletín del Instituto de Historia Argentina y Americana Dr. Emilio Ravignani, Tercera Serie (37), 1142.

Rodríguez, C.

(2008)

Correspondencia con el Doctor José Agustín Molina (1812-1820). Buenos Aires: Academia Nacional de la Historia.

Rojas, R. Archivo Capitular de Jujuy. Buenos Aires: Imp. Coni.

Sábato, H. y Ternavasio, M.

(2011) El voto en la república. Historia del sufragio en el siglo XIX. En R. R. Camańo Semprini, Historia de las elecciones en la Argentina 1805-2011 (pp. 17-134). Buenos Aires: El Ateneo.

62

Salvatore, R.

(2018) Paisanos itinerantes. Orden estatal y experiencia subalterna en Buenos Aires durante la era de Rosas. Buenos Aires: Prometeo

Salvatore, R. A.

(2020)

Re-pensando Paisanos itinerantes. Respuesta a los comentarios de G. Davies, J. Farberman y R. Hora. Boletin del Instituto de Historia Argentina y America- 
na Dr. Emilio Ravignani, (52), 149-165. Recuperado de: http://doi.org/10.34096/bol.rav.n52.7175

Tío Vallejo, G.

(2001)

Antiguo Régimen y liberalismo. Tucumán, 1770-1830. San Miguel de Tucumán: Universidad Nacional de Tucumán, Facultad de Filosofía y Letras.

Verdo, G.

(2002)

El precio del poder. Formas y usos políticos de la representación en la independencia argentina, 18101821. Revista de Indias, LXII (225).

Zamora, Romina

(2008) Fuego en las montañas, 1781: La participación de la plebe de Tucumán en las sublevaciones andinas. Contraste: Revista de Historia Moderna, 13, 9-35.

Zubizarreta, I. y Etchechury-Barrera, M.

(2014) (Coords.). Introducción: «Aquí no hay partidos»: Estudios y perspectivas sobre las facciones y grupos políticos del siglo XIX hispanoamericano. Illes $i$ Imperis, 17. Dossier Facciones y grupos políticos en la Hispanoamérica del siglo XIX. Estudios de historia de las sociedades en el mundo colonial y postcolonial. Recuperado de https:/www.raco.cat/index.php/IllesImperis/article/view/299477/pdf 